\title{
Affective temperaments and procrastination as mediated by emotional reactivity in a nonclinical adult sample
}

\author{
Wtodzimierz Oniszczenko (ID $1 \cdot A, B, C, D, E, F, G$, Ewa Stanisławiak (1D) $2 \cdot A, B, D, E, F$ \\ 1: Faculty of Psychology, University of Warsaw, Warsaw, Poland \\ 2: Faculty of Psychology, University of Economics and Human Sciences, Warsaw, Poland
}

BACKGROUND

The study purpose was to assess the relationship between affective temperaments and procrastination and to examine the role of emotional reactivity as a mediator in this relationship. We hypothesized that depressive, cyclothymic, irritable and anxious temperaments as well as emotional reactivity would be positively correlated with procrastination while the hyperthymic temperament would be negatively correlated, and that emotional reactivity would mediate the relationship between affective temperaments and procrastination.

\section{PARTICIPANTS AND PROCEDURE}

The sample consisted of 315 healthy Caucasian adults (193 women and 122 men) aged 18-69 $(M=31.64, S D=12.14$ ). The Polish version of the Temperament Evaluation of Memphis, Pisa, Paris and San Diego Auto-Questionnaire (TEMPS-A) was used to assess affective temperaments (depressive, cyclothymic, hyperthymic, irritable and anxious). The temperament traits postulated by the regulative theory of temperament were measured with the Formal Characteristics of Behaviour - Temperament Inventory Revised (FCB-TIR). Procrastination was evaluated via a Polish version of the Pure Procrastination Scale (PPS).

\section{RESULTS}

The affective temperaments positively correlated with procrastination, except for hyperthymic temperament (negative correlation). Emotional reactivity and perseveration had a positive relationship with procrastination, while briskness, endurance and rhythmicity had a negative correlation. Cyclothymic temperament and emotional reactivity were found to be significant predictors of procrastination; hyperthymic temperament, endurance and rhythmicity may provide buffers against procrastination.

\section{CONCLUSIONS}

Cyclothymic temperament is an important predictor of procrastination. Emotional reactivity significantly mediated between cyclothymic temperament and procrastination. Hyperthymic temperament, endurance and rhythmicity may provide a buffer against procrastination.

\section{KEY WORDS}

healthy adults; emotional reactivity; affective temperaments; procrastination

CORResPonding AUthor - Prof. Włodzimierz Oniszczenko, Faculty of Psychology, University of Warsaw, 5-7 Stawki Str., 00-183 Warsaw, Poland, e-mail: wlodek@psych.uw.edu.pl

AUthors' CONTRIBUtion - A: Study design - B: Data collection - C: Statistical analysis - D: Data interpretation .

E: Manuscript preparation · F: Literature search · G: Funds collection

TO CITE THIS ARTICLE - Oniszczenko, W., \& Stanisławiak, E. (2020). Affective temperaments and procrastination as mediated by emotional reactivity in a nonclinical adult sample. Current Issues in Personality Psychology, 8(2), 92-99. RECEIVED 27.02.2020 • REVIEWED 04.04.2020 • ACCEPTED 11.05.2020 • PUBLISHED 08.06.2020 


\section{BACKGROUND}

Procrastination is a widely prevalent phenomenon with numerous definitions and methods of measurement (Svartdal \& Steel, 2017). According to Steel (2007), to "procrastinate is to voluntarily delay an intended course of action despite expecting to be worse off for the delay" (p. 66). For example, Tice and Baumeister (1997) showed that the early stage of procrastination is associated with benefits such as positive emotions, but after a time this delay leads to unpleasant tension. Steel's (2007) aforementioned definition of procrastination refers to the so-called pure procrastination or chronic procrastination, that is, a mode of functioning in which an individual constantly and irrationally delays performing a task. Chu and Choi (2005) consider such persons passive procrastinators as they delay completing a task on time due to their indecision and inaction. In contrast, active procrastination is considered to be its "positive" form, because active procrastinators usually delay completion of tasks in order to create favourable working conditions for themselves (i.e., working better under pressure; Chu \& Choi, 2005).

Tibbett and Ferrari (2019) suggest that procrastination may result from an individual's indecision and regret about previous decisions regarding education, finances or family life. However, numerous authors have proposed an association between procrastination and personality traits, particularly conscientiousness (Boysan \& Kiral, 2017), extraversion, neuroticism (Kim, Fernandez, \& Terrier, 2017) and anxiety (Constantin, English, \& Mazmanian, 2018). Procrastination is also related to metacognition factors, such as negative beliefs about uncontrollability and danger (Fernie, McKenzie, Nikčević, Caselli, \& Spada, 2016), as well as with negative affect, namely depression (Fernie, Bharucha, Nikčević, Marino, \& Spada, 2017; Ozer, O'Callaghan, Bokszczanin, Ederer, \& Essau, 2014). However, it is worth noting that depression, neuroticism and low self-efficacy in different situations may collectively represent at least one of the causes of procrastination (Steel, 2007). Also, Beutel et al. (2016) indicated a link between procrastination and greater stress, depression, anxiety and fatigue, in addition to reduced satisfaction across life domains.

Several authors posit that procrastination may be an important component of a short-term mood regulation strategy playing a significant role in mood repair (Pychyl \& Sirois, 2016; Sirois \& Pychyl, 2013; Wypych, Matuszewski, \& Dragan, 2018; Zhang, Liu, $\&$ Feng, 2019). On the other hand, mood disorders are associated with affective temperaments that are traitrelated manifestations, stable over time (Kawamura et al., 2010) and having cultural specificities (Vázquez, Tondo, Mazzarini, \& Gonda, 2012). According to Akiskal and Akiskal (2005), affective temperaments play a significant role in the predisposition to mood disor- ders such as depression, anxiety and bipolar disorder. Five affective temperaments have been identified: "the hyperthymic one characterized by emotional intensity, the cyclothymic one by emotional instability, the depressive one by a low energy level, and the irritable one by an excessive response to stimuli" (Rovai et al., 2013, p. 2065). Finally, anxious temperament was added and "described as constant worrying and a tendency to express psychological tension, in the form of psychosomatic symptoms" (Dembińska-Krajewska \& Rybakowski, 2014, p. 263).

These temperaments also correlate with the traits derived from the best-known personality models, such as the five-factor personality model (Akiskal \& Akiskal, 2005; Rovai et al., 2013). For example, positive correlations have been demonstrated between neuroticism (as measured by the NEO-Five Factor Inventory) and all affective temperaments, except the hyperthymic temperament (Blöink, Briegera, Akiskal, \& Marneros, 2005; Oniszczenko \& Stanisławiak, 2019).

Strelau's (1998) regulative theory of temperament (RTT) assumes that temperamental traits are present from infancy and play an important role in all life situations, especially stressful ones. The RTT postulates seven temperament traits as follows: "Briskness (BR, the tendency to react quickly and perform activities at a high tempo), perseveration ( $\mathrm{PE}$, the tendency to maintain and repeat behaviours after the situation that elicited them has changed), sensory sensitivity (SS), the ability to react to sensory stimuli of low stimulative value and to detect minor differences between sensory stimuli values), emotional reactivity (ER, the tendency to have intense reactions to emotogenic stimuli, manifested in high emotional sensitivity and low emotional resistance), endurance (EN, the ability to react appropriately in situations demanding long-lasting, high-stimulative activity), activity (AC, the tendency to perform high-stimulative behaviours or to supply external stimulation through the behaviour undertaken) and rhythmicity (RT, the tendency to keep regular time intervals between similar reactions, which manifests in eating and sleeping habits and a driven lifestyle)" (Cyniak-Cieciura, Zawadzki, \& Strelau, 2018, pp. 118-120).

Researchers have demonstrated genetic correlations between the RTT and the Big Five personality traits, specifically neuroticism with ER and PE and extraversion with BR, EN and AC (Kandler et al., 2012). ER has been viewed as a temperamental risk factor for emotional disturbances when facing stressful life situations, and it may play a role similar to that of better-known personality traits, such as neuroticism and anxiety, in times of distress. For example, ER has been shown to be a significant predictor of depression (Hintsa et al., 2016) and trauma symptoms (Rzeszutek, Oniszczenko, Schier, Biernat-Kałuża, \& Gasik, 2016). In another study, Dragan, Dragan, Kononowicz, and Wells (2012) suggested that ER (as well as PE and BR) 
is associated with three metacognition components: positive beliefs about worry and negative beliefs about thoughts concerning uncontrollability and danger and the consequences of not controlling thoughts. Moreover, ER may have both direct and metacognitively mediated effects on state anxiety.

In a recent study, Oniszczenko, Stanisławiak, Dembińska-Krajewska, and Rybakowski (2017) found that ER and PE are also positively related to affective temperaments (depressive, cyclothymic, irritable and anxious), with the exception of the hyperthymic temperament, which is most likely linked to the AC trait. Notably, affective temperaments and RTT traits, regardless of the differences between them, have a common genetic foundation associated with dopaminergic and serotonergic systems (Oniszczenko et al., 2017).

The purpose of this study, therefore, was to assess the relationship between affective temperaments and procrastination according to Steel (2007) and to examine ER as a mediator in this relationship in a nonclinical adult sample. ER appears responsible for the emergence and intensity of emotions and emotional resistance, or low ability to control emotional reactions to emotion-inducing stimuli (Strelau, 2008; Strelau \& Zawadzki, 2011). We thus assumed that ER plays a significant role in procrastination as a mediator between affective temperaments and procrastination, leading to the hypothesis that: (1) depressive, cyclothymic, irritable and anxious temperaments are positively correlated with procrastination, while the hyperthymic temperament is negatively correlated with procrastination; (2) ER is positively correlated with and can directly affect procrastination; and (3) ER mediates the relationship between affective temperaments and procrastination.

\section{PARTICIPANTS AND PROCEDURE}

\section{PARTICIPANTS}

The study sample comprised 315 healthy Caucasian adults (193 women and 122 men) aged from 18 to 69 years $(M=31.64, S D=12.14)$. The participants were recruited from a nonclinical population. In terms of education level, 173 participants had postsecondary education, 132 had secondary education, and 7 had primary education ( 3 participants did not provide any information about their education). The participants were recruited directly by the interviewers, who contacted students of various faculties, their colleagues, friends, parents and, in the case of working students, their co-workers. The inclusion criteria were age $\geq 18$ years and an absence of self-reported mental problems.

The study was anonymous, and participation was voluntary. All self-report questionnaires were administered in a standard manner. All participants provided informed consent before they were included in the study, and they did not receive any compensation. The research project was approved by the local Research Ethics Commission at the Faculty of Psychology, University of Warsaw.

\section{MEASUREMENTS}

Temperament Evaluation of Memphis, Pisa, Paris, and San Diego Auto-Questionnaire. Affective temperaments were assessed using the Polish version of the Temperament Evaluation of Memphis, Pisa, Paris, and San Diego Auto-Questionnaire (TEMPS-A; Akiskal, Akiskal, Haykal, Manning, \& Connor, 2005; Borkowska et al., 2010). The TEMPS-A is a self-report instrument comprising 110 items (109 for men) using a yes/ no response format. This instrument contains five scales (Cronbach's $\alpha$ values for the current sample follow in parentheses): depressive $(\alpha=.70)$, cyclothymic $(\alpha=.77)$, hyperthymic $(\alpha=.75)$, irritable $(\alpha=.76)$ and anxious $(\alpha=.83)$. For each answer, a 'yes' response was scored as 1 , and a 'no' response as 0 . These scores were added, then divided by the number of items belonging to each affective temperament scale (21 for each of the first four categories of temperaments and 26 for the last category, i.e., anxious temperament).

Formal Characteristics of Behaviour - Temperament Inventory Revised. The RTT traits were assessed using Cyniak-Cieciura, Zawadzki, and Strelau's (2016) Formal Characteristics of Behaviour - Temperament Inventory Revised (FCB-TIR). The 100 items of this inventory employ a 4-point Likert response scale (15 items each for the BR, PE, SS, ER, EN and AC scales and 10 items for the RT scale). The Cronbach's $\alpha$ values for the FCB-TIR scales in the current sample were as follows: BR: $\alpha=.79$, PE: $\alpha=.75$, SS: $\alpha=.76$, ER: $\alpha=.85$, EN: $\alpha=.83$, AC: $\alpha=.86$, and RT: $\alpha=.83$. Higher total scores on the FCB-TIR scales indicate higher levels of the respective traits.

Pure Procrastination Scale. To assess procrastination, a Polish version (Stępień \& Cieciuch, 2013) of the Pure Procrastination Scale (PPS) developed by Steel (2010) was used. The PPS is a self-report measure of 12 items directly related to procrastination, rated using a 5-point Likert scale (1-5). Higher scores indicate greater agreement. The Polish version of the PPS had a Cronbach's $\alpha$ value of .89 .

\section{STATISTICAL ANALYSIS}

The statistical analysis was performed using IBM SPSS Statistics 24 (IBM Corp., 2016). Descriptive statistics such as means and standard deviations of the main variables were recorded, and relationships among variables were examined through Pearson product-moment coefficients. A hierarchical multi- 
ple regression analysis was also used to estimate the effects of affective temperaments and RTT traits as procrastination predictors. The mediation analyses were conducted using the PROCESS macro for SPSS (Model 4, Hayes, 2013). Direct and indirect effects were estimated via the bootstrapping procedure with 5,000 sample draws and bias-corrected standard errors (Preacher \& Hayes, 2008).

\section{RESULTS}

All variables, with the exception of the irritable temperament (skew: 1.13, kurtosis: 1.17), had skewness ranging from -.32 to .68 and kurtosis ranging from -.71 to .71 , indicating compatibility with a normal distribution (Tabachnick \& Fidell, 2013). The descriptive statistics, Cronbach's $\alpha$ values and bivariate correlations between procrastination and the temperament traits are presented in Table 1 and show that the correlations between the TEMPS-A and FCB-TIR and procrastination scales were small to medium (an absolute value of $r$ of .1 was classified as small, .3 as medium, and .5 as large per Cohen, 1988).

Table 1

Descriptive statistics and correlations for temperament and procrastination $(n=315)$

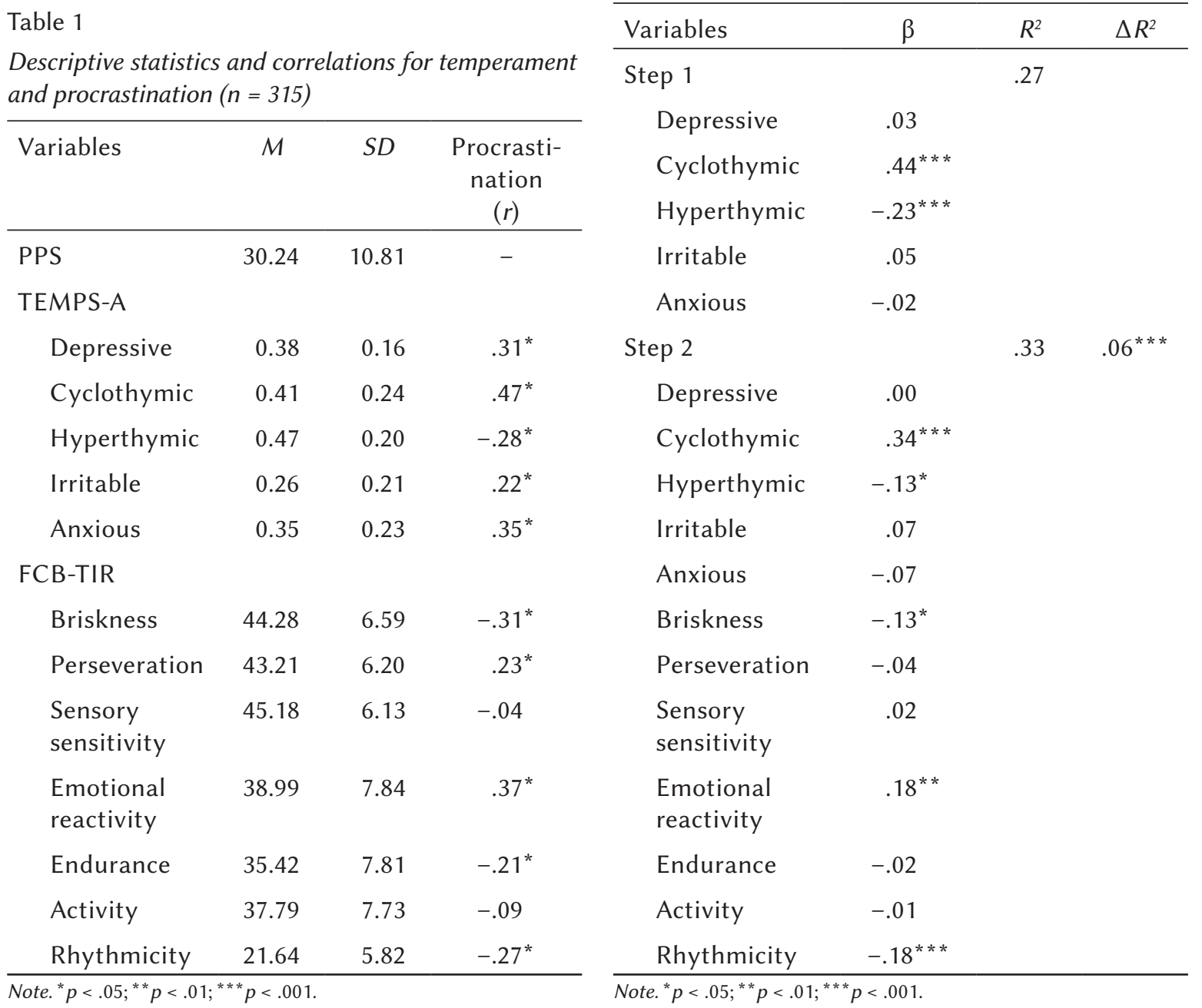

Procrastination positively correlated with the affective temperaments, except for the hyperthymic temperament (negative correlation). The correlations between procrastination and $\mathrm{BR}, \mathrm{EN}$ and $\mathrm{RT}$ were negative, while the correlations between procrastination and PE and ER were positive. No significant correlation existed between SS, AC and procrastination.

Additionally, we conducted a hierarchical multiple regression analysis to determine the extent to which affective temperaments and RTT dimensions can be viewed as predictors of procrastination. Based on the regression coefficients, only cyclothymic temperament and emotional reactivity were found to be significant predictors of procrastination in the studied sample ( $\beta$ coefficients .34 and .18, respectively). In turn, hyperthymic temperament, EN and RT may provide buffers against procrastination ( $\beta$ coefficients $-.13,-.13$, and -.18$)$. The results are summarized in Table 2.

Table 2

Hierarchical multiple regression analysis of affective temperaments and RTT temperament traits as predictors of procrastination $(n=315)$ 


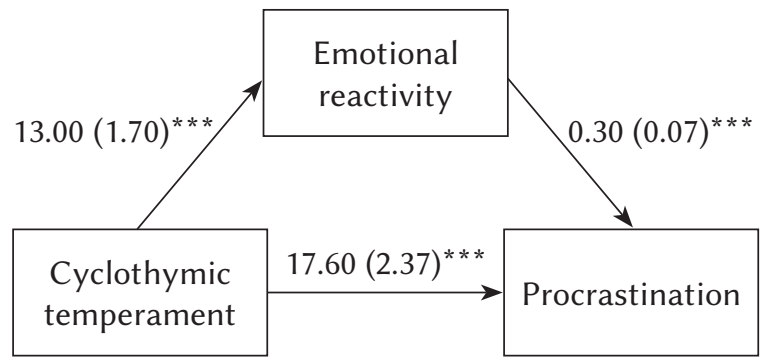

Figure 1. Mediating effect of emotional reactivity in relationship between cyclothymic temperament and procrastination. Unstandardized coefficients are reported, with standard errors in parentheses. ${ }^{* * *} p<.001$

Next, a mediation analysis with a bootstrapping procedure using ER as a mediator between cyclothymic temperament and procrastination was performed. The analysis revealed a significant indirect effect of cyclothymic temperament on procrastination through ER [effect $=3.90, S E=1.13,95 \%$ $\mathrm{CI}=(1.95,6.27)]$. The individual pathways of the mediation analysis are displayed in Figure 1.

\section{DISCUSSION}

The aim of this study was to assess the relationship between affective temperaments and procrastination and to examine the mediating role of emotional reactivity in this relationship. We hypothesized that depressive, cyclothymic, irritable and anxious temperaments, as well as emotional reactivity, would be positively correlated with procrastination yet negatively correlated with the hyperthymic temperament. Additionally, we predicted that emotional reactivity would mediate the relationship between affective temperaments and procrastination.

Confirming these hypotheses, we found significant positive relationships between cyclothymic, anxious, depressive, and irritable temperaments and procrastination and a significant negative correlation between the hyperthymic temperament and procrastination. Congruent with our expectations, we also observed significant positive relationships between ER and procrastination and between PE and procrastination. In contrast, the correlations of procrastination with BR, EN and RT were significantly negative (no correlations between SS and AC and procrastination were found). Based on the hierarchical regression analysis, only cyclothymic temperament and emotional reactivity significantly predicted procrastination, while hyperthymic temperament, EN, and RT may serve as buffers against procrastination.

These findings indicate that the two main traits of the cyclothymic temperament may be combined with procrastination. The first one is a pattern of alternation between hypomanic and depressive subclinical moods, cognitions, and behaviours (Vázquez \& Gonda, 2013). The cyclothymic temperament is primarily characterized by significant instability of mood and energy expressed as rapid changes, accompanied by excessive emotional sensitivity (Hantouche \& Perugi, 2012). Constantin et al. (2018) demonstrated that depression and anxiety are associated with procrastination and that rumination serves as a mediator between anxiety and procrastination, as well as between depression and procrastination. As Constantin et al. (2018) suggest, individuals experiencing high levels of depression and anxiety may intentionally delay tasks as a result of negative repetitive thoughts, particularly thoughts regarding past events. The second important trait of cyclothymic temperament is unstable self-esteem that swings from low self-confidence to overconfidence (Vázquez \& Gonda, 2013). Several authors (e.g., Boysan \& Kiral, 2017; Hajloo, 2014) have proposed that low self-esteem may be the primary significant predictor of procrastination.

A more detailed description of cyclothymic temperament indicates a number of important features of this temperament that may be associated with procrastination. Cyclothymic individuals, during the phase of increased activity and energy for action, may show excessive trust in themselves, excessive self-esteem, carefree attitudes, unequal quantity and quality of work, lack of concern for the consequences of their own actions, but also a sense of guilt over previous actions. At the same time, people with a high level of cyclothymic temperament are considered individuals capable of sharp and creative thinking (Rovai et al., 2013; Vázquez \& Gonda, 2013). According to Perugi, Hantouche, and Vannucchi (2017), excessive emotional responses in stressful situations, a tendency to engage in potentially risky situations, and high mood instability in cyclothymic individuals can be associated with a number of adverse psychological and behavioural consequences, including procrastination. Cyclothymic temperament is typically a mix of emotional reactivity, sensation seeking, and mood instability, but also impulsiveness, observed in procrastination (Wypych et al., 2018).

Our results also revealed a significant association between emotional reactivity as an RTT trait and procrastination. This result concurs somewhat with the results of other studies showing that neuroticism (analogous to ER) is often positively correlated with procrastination, while the relationship between extraversion (equivalent to BR and EN) and procrastination is more unclear (Kim et al., 2017; Steel, 2007).

Although Steel (2010) argues that distinguishing different types of procrastination (e.g., avoidant or arousal) is unwarranted, Boysan and Kiral (2017) propose that procrastination may be a coping mechanism to prevent worry and anxiety in some situations. In an earlier study, Ferrari and Tice (2000) indicated that 
chronic procrastinators engage in procrastination only when the upcoming task is potentially threatening, so procrastination might also serve as an avoidance mechanism. Furthermore, de Palo, Monacis, Miceli, Sinatra, and Di Nuovo (2017; see also Mann, 2016) suggested that decisional procrastination is one type of coping, a so-called defensive avoidance. Emotional reactivity is responsible for the emergence and intensity of emotions and emotional resistance, or low ability to control emotional reactions to strong emotogenic stimuli (Strelau, 2008). Therefore, emotional reactivity may activate the procrastinating mechanism to protect against excessive distress. In turn, Rovai et al. (2013) demonstrated that the cyclothymic temperament is manifested in rapid mood changes and lack of emotional stability. Thus, the relationship between cyclothymic temperament and emotional reactivity as a mediator between cyclothymic temperament and procrastination seems to be clear.

As shown by Blöink et al. (2005), extraversion is strongly associated with hyperthymic temperament (see also Akiskal \& Akiskal, 2005). This result suggests that, compared to people with other affective temperaments, people with a dominant hyperthymic temperament may better control threatening situations. Therefore, a high level of hyperthymic temperament may lessen or moderate procrastination. Meanwhile, Kim et al. (2017) state that extraverts might be less likely to procrastinate because of their activity and assertiveness, although they can engage in active procrastination in order to be more efficient. The negative correlation between RT and procrastination is also of interest, given that RT is a trait indicating regularity in performing everyday, homogeneous reactions. Thus, more rhythmic individuals may be less prone to procrastination. We propose that RT should be considered in future studies on procrastination.

Several limitations of our study must be taken into account. This research was cross-sectional in nature, prohibiting any definite conclusions about the direction of the relationships between procrastination and its correlates. Personality may play a significant role in procrastination, but further longitudinal studies are needed to verify its potential role. Also, we used self-report measures, which are highly susceptible to a number of biases. They do not allow assessment of the individual's intention for behavioural delay as the core characteristic of procrastination. None of the findings from this study were confirmed in behavioural or observational studies. Finally, the study employed a healthy adult sample, limiting the generalizability of its findings to clinical populations.

\section{CONCLUSIONS}

The cyclothymic temperament and ER were conducive to procrastination, while the hyperthymic tempera- ment, EN, and RT may buffer against procrastination. Emotional reactivity was a significant mediator between cyclothymic temperament and procrastination.

\section{ACKNOWLEDGEMENTS}

The present study was supported by Grant No. BST 1868-01-2018 from the University of Warsaw. This research did not receive any specific grants from funding agencies in the public, commercial or not-for-profit sectors.

\section{RefERENCES}

Akiskal, K. K., \& Akiskal, H. S. (2005). The theoretical underpinnings of affective temperaments: Implications for evolutionary foundations of bipolar disorder and human nature. Journal of Affective Disorders, 85, 231-239. https://doi.org/10.1016/j.jad.2004.08.002

Akiskal, H. S., Akiskal, K. K., Haykal, R. F., Manning, J. S., \& Connor, P. D. (2005). TEMPS-A: Progress towards validation of a self-rated clinical version of the Temperament Evaluation of the Memphis, Pisa, Paris, and San Diego Autoquestionnaire. Journal of $A f-$ fective Disorders, 85, 3-16. https://doi.org/10.1016/j. jad.2004.12.001

Beutel, M. E., Klein, E. M., Aufenanger, S., Brähler, E., Dreier, M., Müller, K. W., Quiring, O., Reinecke, L., Schmutzer, G., Stark, B., \& Wölfling, K. (2016). Procrastination, distress and life satisfaction across the age range - a German representative community study. PLoS One, 11, e0148054. https://doi. org/10.1371/journal.pone.0148054

Blöink, R., Brieger, P., Akiskal, H. S., \& Marneros, A. (2005). Factorial structure and internal consistency of the German TEMPS-A scale: Validation against the NEO-FFI questionnaire. Journal of Affective Disorders, 85, 77-83. https://doi.org/10.1016/S01650327(03)00101-0

Borkowska, A., Rybakowski, J. K., Drożdż, W., Bieliński, M., Kosmowska, M., Rajewska-Rager, A., Buciński, A., Akiskal, K. K., \& Akiskal, H. S. (2010). Polish validation of the TEMPS-A: The profile of affective temperaments in a college student population. Journal of Affective Disorders, 123, 36-41. https://doi.org/10.1016/j.jad.2009.09.024

Boysan, M., \& Kiral, E. (2017) Associations between procrastination, personality, perfectionism, self-esteem and locus of control. British Journal of Guidance \& Counselling, 45, 284-296. https://doi.org/10. 1080/03069885.2016.1213374

Chu, A. H. C., \& Choi, J. N. (2005). Rethinking procrastination: Positive effects of "active" procrastination behavior on attitudes and performance. The Journal of Social Psychology, 145, 245-264. https:// doi.org/10.3200/SOCP.145.3.245-264 
Cohen, J. (1988). Statistical power analysis for the behavioral sciences (2nd ed.). Hillsdale, NJ: Erlbaum.

Constantin, K., English, M. M., \& Mazmanian, D. (2018). Anxiety, depression, and procrastination among students: Rumination plays a larger mediating role than worry. Journal of Rational-Emotive \& Cognitive-Behavior Therapy, 15, 15-27. https:// doi.org/10.1007/s10942-017-0271-5

Cyniak-Cieciura, M., Zawadzki, B., \& Strelau, J. (2016). Formalna charakterystyka zachowania kwestionariusz temperamentu: wersja zrewidowana - FCZ-KT(R). Podręcznik [The Formal Characteristic of Behaviour - Temperament Inventory Revised. Manual] Warszawa: Pracownia Testów Psychologicznych PTP.

Cyniak-Cieciura, M., Zawadzki, B., \& Strelau, J. (2018). The development of the revised version of the Formal Characteristic of Behaviour - Temperament Inventory FCB-TI(R). Personality and Individual Differences, 127, 117-126. https://doi. org/10.1016/j.paid.2018.01.036

Dembińska-Krajewska, D., \& Rybakowski, J. (2014). The Temperament Evaluation of Memphis, Pisa and San Diego Autoquestionnaire (TEMPS-A) - an important tool to study affective temperaments. Psychiatria Polska, 48, 261-276.

de Palo, V., Monacis, L., Miceli, S., Sinatra, M., \& Di Nuovo, S. (2017). Decisional procrastination in academic settings: The role of metacognitions and learning strategies. Frontiers in Psychology, 8, 973. https://doi.org/10.3389/fpsyg.2017.00973

Dragan, M., Dragan, W. Ł, Kononowicz, T., \& Wells, A. (2012). On the relationship between temperament, metacognition, and anxiety: Independent and mediated effects. Anxiety, Stress \& Coping: An International Journal, 25, 697-709. https://doi.org/ 10.1080/10615806.2011.630071

Fernie, B. A., Bharucha, Z., Nikčević, A. V., Marino, C., \& Spada, M. M. (2017). A metacognitive model of procrastination. Journal of Affective Disorders, 210, 196-203. https://doi.org/10.1016/j.jad.2016.12.042

Fernie, B. A., McKenzie, A. M., Nikčević, A. V., Caselli, G., \& Spada, M. M. (2016). The contribution of metacognitions and attentional control to decisional procrastination. Journal of Rational-Emotive \& Cognitive-Behavior Therapy, 34, 1-13. https:// doi.org/10.1007/s10942-015-0222-y

Ferrari, J. R., \& Tice, D. M. (2000). Procrastination as a self-handicap for men and women: a task avoidance strategy in a laboratory setting. Journal of Research in Personality, 34, 73-83. https://doi.org/ 10.1006/jrpe.1999.2261

Hajloo, N. (2014). Relationships between self-efficacy, self-esteem and procrastination in undergraduate psychology students. Iranian Journal of Psychiatry and Behavioral Sciences, 8, 42-49.

Hantouche, E., \& Perugi, G. (2012). Should cyclothymia be considered as a specifc and distinct bipolar dis- order? Neuropsychiatry, 2, 407-414. https://doi.org/ 10.2217/npy. 12.45

Hayes, A. F. (2013). An introduction to mediation, moderation, and conditional process analysis: a regression-based approach. New York, NY: Guilford Press. Hintsa, T., Wesolowska, K., Elovainio, M., Strelau, J., Pulkki-Råback, L., \& Keltikangas-Järvinen, L. (2016). Associations of temporal and energetic characteristics of behavior with depressive symptoms: a population-based longitudinal study within Strelau's regulative theory of temperament. Journal of Affective Disorders, 197, 196-204. https://doi.org/ 10.1016/j.jad.2016.02.056

IBM Corp. (2016). IBM SPSS Statistics for Windows, Version 24.0. Armonk, NY: IBM Corp.

Kandler, C., Held, L., Kroll, C., Bergeler, A., Riemann, R., \& Angleitner, A. (2012). Genetic links between temperamental traits of the regulative theory of temperament and the Big Five. Journal of Individual Differences, 33, 197-204. https://doi. org/10.1027/1614-0001/a000068

Kawamura, Y., Akiyama, T., Shimada, T., Minato, T., Umekage, T., Noda, Y., Ukawa, K., Hashidume, C., Sakai, Y., Otowa, T., Sasaki, T., \& Akiskal, H. S. (2010). Six-year stability of affective temperaments as measured by TEMPS-A. Psychopathology, 43, 240-247. https://doi.org/10.1159/000313522

Kim, S., Fernandez, S., \& Terrier, L. (2017). Procrastination, personality traits, and academic performance: When active and passive procrastination tell a different story. Personality and Individual Differences, 108, 154-157. https://doi.org/10.1016/j. paid.2016.12.021

Mann, L. (2016). Procrastination revisited: a commentary. Australian Psychologist, 51, 47-51. https://doi. org/10.1111/ap. 12208

Oniszczenko, W., \& Stanisławiak, E. (2019). Five Factor Personality Model versus affective temperaments: a study in a nonclinical Polish sample. Current Issues in Personality Psychology, 7, 15-23. https://doi.org/10.5114/cipp.2019.82751

Oniszczenko, W., Stanisławiak, E., Dembińska-Krajewska, D., \& Rybakowski, J. (2017). Regulative theory of temperament versus affective temperaments measured by the Temperament Evaluation of Memphis, Pisa, Paris and San Diego Auto-questionnaire (TEMPS-A): a study in a non-clinical Polish sample. Current Issues in Personality Psychology, 5, 73-82. https://doi.org/10.5114/cipp.2017.65847

Ozer, B. U., O'Callaghan, J., Bokszczanin, A., Ederer, E., \& Essau, C. (2014). Dynamic interplay of depression, perfectionism and self-regulation on procrastination. British Journal of Guidance \& Counselling, 42, 309-319. https://doi.org/10.1080/03069885.2014. 896454

Perugi, G., Hantouche, E., \& Vannucchi, G. (2017). Diagnosis and treatment of cyclothymia: The "primacy" of temperament. Current Neuropharmacol- 
ogy, 15, 372-379. https://doi.org/10.2174/157015 9X14666160616120157

Preacher, K. J., \& Hayes, A. F. (2008). Asymptotic and resampling strategies for assessing and comparing indirect effects in multiple mediator models. Behavior Research Methods, 40, 879-891. https:// doi.org/10.3758/BRM.40.3.879

Pychyl, T. A., \& Sirois, F. M. (2016). Procrastination, emotion regulation, and well-being. In F. M. Sirois \& T. A. Pychyl (Eds.), Procrastination, health, and well-being (pp. 163-188). San Diego, CA: Elsevier Academic Press,

Rovai, L., Maremmani, A. G., Rugani, F., Bacciardi, S., Pacini, M., Dell'Osso, L., Akiskal, H. S., \& Maremmani, I. (2013). Do Akiskal \& Mallya's affective temperaments belong to the domain of pathology or to that of normality? European Review for Medical and Pharmacological Science, 17, 2065-2079.

Rzeszutek, M., Oniszczenko, W., Schier, K., BiernatKałuża, E., \& Gasik, R. (2016). Temperament traits, social support, and trauma symptoms among HIV/AIDS and chronic pain patients. International Journal of Clinical and Health Psychology, 16, 137146. https://doi.org/10.1016/j.ijchp.2015.10.001

Sirois, F. M., \& Pychyl, T. A. (2013). Procrastination and the priority of short-term mood regulation: Consequences for future self. Social and Personality Psychology Compass, 7, 115-127. https://doi. org/10.1111/spc3.12011

Steel, P. (2007). The nature of procrastination: a metaanalytic and theoretical review of quintessential self-regulatory failure. Psychological Bulletin, 133, 65-94. https://doi.org/10.1037/0033-2909.133.1.65

Steel, P. (2010). Arousal, avoidant and decisional procrastinators: Do they exist? Personality and Individual Differences, 48, 926-934. https://doi.org/10. 1016/j.paid.2010.02.025.

Stępień, M., \& Cieciuch, J. (2013). Pure procrastination scale. Unpublished manuscript. Warszawa: Instytut Psychologii UKSW.

Strelau, J. (1998). Temperament: a psychological perspective. New York, NY: Plenum Press.

Strelau, J. (2008). Temperament as a regulator of behaviour. After fifty years of research. New York, NY: Werner.

Strelau, J., \& Zawadzki, B. (2011). Fearfulness and anxiety in research on temperament: Temperamental traits are related to anxiety disorders. Personality and Individual Differences, 50, 907-915. https://doi.org/10.1016/j.paid.2010.07.008

Svartdal, F., \& Steel, P. (2017). Irrational delay revisited: Examining five procrastination scales in a global sample. Frontiers in Psychology, 8, 1927. https://doi.org/10.3389/fpsyg.2017.01927

Tabachnick, B. G., \& Fidell, L. S. (2013). Using multivariate statistics (6th ed.). Boston, MA: Pearson.

Tibbett, T. P., \& Ferrari, J. R. (2019). Return to the origin: What creates a procrastination identity? Cur- rent Issues in Personality Psychology, 7, 1-7. https:// doi.org/10.5114/cipp.2018.75648

Tice, D. M., \& Baumeister, R. F. (1997). Longitudinal study of procrastination, performance, stress, and health: The costs and benefits of dawdling. Psychological Science, 8, 454-458. https://doi.org/ 10.1111/j.1467-9280.1997.tb00460.x

Vázquez, G. H., \& Gonda, X. (2013). Affective temperaments and mood disorders: a review of current knowledge. Current Psychiatry Reviews, 9, 21-32. https://doi.org/10.2174/157340013805289617

Vázquez, G. H., Tondo, L., Mazzarini, L., \& Gonda, X. (2012). Affective temperaments in general population: a review and combined analysis from national studies. Journal of Affective Disorders, 139, 18-22. https://doi.org/10.1016/j.jad.2011.06.032

Wypych, M., Matuszewski, J., \& Dragan, W. Ł. (2018). Roles of impulsivity, motivation, and emotion regulation in procrastination - path analysis and comparison between students and non-students. Frontiers in Psychology, 9, 891. https://doi.org/10.3389/ fpsyg.2018.00891

Zhang, S., Liu, P., \& Feng, T. (2019). To do it now or later: The cognitive mechanisms and neural substrates underlying procrastination. WIREs Cognitive Science, 10, 1-20. https://doi.org/10.1002/wcs.1492 